\title{
GDO Artificial Intelligence-Based Switching PID Baseline Feedback Linearization Method: Controlled PUMA Workspace
}

\author{
Farzin Piltan \\ Industrial Electrical and Electronic Engineering SanatkadeheSabze Pasargad. CO (S.S.P. Co), NO:16, PO.Code \\ 71347-66773, Fourth floor, Dena Apr, Seven Tir Ave, Shiraz, Iran \\ SSP.ROBOTIC@gmail.com \\ Reza Bayat \\ Industrial Electrical and Electronic Engineering SanatkadeheSabze Pasargad. CO (S.S.P. Co), NO:16, PO.Code \\ 71347-66773, Fourth floor, Dena Apr, Seven Tir Ave , Shiraz , Iran \\ SSP.ROBOTIC@yahoo.com \\ Saleh Mehara \\ Industrial Electrical and Electronic Engineering SanatkadeheSabze Pasargad. CO (S.S.P. Co), NO:16, PO.Code \\ 71347-66773, Fourth floor, Dena Apr, Seven Tir Ave , Shiraz , Iran \\ Javad Meigolinedjad \\ Industrial Electrical and Electronic Engineering SanatkadeheSabze Pasargad. CO (S.S.P. Co), NO:16, PO.Code \\ 71347-66773, Fourth floor, Dena Apr , Seven Tir Ave , Shiraz , Iran
}

\begin{abstract}
Congetive method is used in this research to create portfilo of movement robot manipulator. Gradient descent (GD) artificial intelligence based switching feedback linearization controller was used and robot's postures and trajectory were expected in MATLAB/SIMULINK environment. Feedback linearization controller (CTC) is an influential nonlinear controller to certain systems which it is based on feedback linearization and computes the required torques using the nonlinear feedback control law in certain systems. Practically a large amount of systems have uncertainties accordingly this method has a challenge. Switching feedback linearization controller is a significant combination nonlinear stable-robust controller under condition of partly uncertain dynamic parameters of system. This technique is used to control of highly nonlinear systems especially in nonlinear time varient nonlinear dynamic system. To increase the stability and robustness with regards to improve the robustness switching methodology is applied to feedback linearization controller. Lyapunov stability is proved in proposed controller based on switching function. To compensate for the dependence on switching parameters baseline methodology is used.The nonlinear model dynamic formulation problem in uncertain system can be solved by using artificial intelligence theorem. Fuzzy logic theory is used to estimate the system dynamic. Forward kinematics implemented the manipulator's movements. Results validated the robot's range of possible postures and trajectories.
\end{abstract}

Index Terms - Feedback linearization controller, sliding switching mode methodology, Mamdani's fuzzy inference system, gradient descent optimization, artificial based controller

\section{INTRODUCTION}

In modern usage, the word of control has many meanings, this word is usually taken to mean regulate, direct or command. The word feedback plays a vital role in the advance engineering and science. The conceptual frame work in Feed-back theory has developed only since world war II. In the twentieth century, there was a rapid growth in the application of feedback controllers in process industries. According to Ogata, to do the first significant work in three-term or PID controllers which Nicholas Minorsky worked on it by automatic controllers in 1922. In 1934, Stefen Black was invention of the feedback amplifiers to develop the negative feedback amplifier[3]. Negative feedback invited communications engineer Harold Black in 1928 and it occurs when the output is subtracted from the input. Automatic control has played an important role in advance science and engineering and its extreme importance in many industrial applications, i.e., aerospace, mechanical engineering and robotic systems. Controller is a device which can sense information from linear or nonlinear systems to improve the systems performance [1-3]. The main targets in designing control systems are stability, good disturbance rejection, and small tracking error[4-5]. Several industrial systems are controlled by linear 
methodologies (e.g., Proportional-Derivative (PD) controller, Proportional- Integral (PI) controller or Proportional- Integral-Derivative (PID) controller), but when system works in various situation and have uncertainty in dynamic models nonlinear methodology is introduced. In some applications systems are used in an unknown and unstructured environment, therefore strong mathematical tools used in new control methodologies to design nonlinear robust. Nonlinear controllers are divided into to six groups, namely, feedback linearization (computed-torque control), passivity-based control, sliding mode control (variable structure control), artificial intelligence control, Lyapunov-based control and adaptive control[1, 6-14].

Feedback linearization controller (CTC) is a powerful nonlinear controller which it widely used in control of nonlinear systems. It is based on feedback linearization and computes the required arm torques using the nonlinear feedback control law. This controller works very well when all dynamic and physical parameters are known but when the system has variation in dynamic parameters, in this situation the controller has no acceptable performance[14]. In practice, most of physical systems parameters are unknown or time variant, therefore, computed torque like controller used to compensate nonlinear dynamic equation of this system[1, 6]. Research on feedback linearization controller is significantly growing on nonlinear system application which has been reported in [1-5, 6-7]. Vivas and Mosquera [6] have proposed a predictive functional controller and compare to feedback linearization controller for tracking response in uncertain environment. However both controllers have been used in feedback linearization, but predictive strategy gives better result as a performance. A computed torque control with non parametric regression models have been presented for a robot arm[7]. This controller also has been problem in uncertain dynamic models. Based on [1-5]and [6-7] feedback linearization controller is a significant nonlinear controller to certain systems which it is based on feedback linearization and computes the required arm torques using the nonlinear feedback control law. When all dynamic and physical parameters are known, feedback linearization controller works fantastically; practically a large amount of systems have uncertainties, therefore switching sliding feedback linearization controller is one of the best case to solve this challenge. Switching sliding feedback linearization controller is a powerful nonlinear robust controller under condition of partly uncertain dynamic parameters of system. This methodology is used to control of highly nonlinear systems especially for nonlinear systems. This methodology is used to solve two important challenges in pure feedback linearization controller, namely; stability and robustness. However this methodology works very good especially in nonlinear systems but it has an important challenges; nonlinear system's dynamic formulation in uncertain dynamic parameter. The nonlinear dynamic formulation problem in uncertain system is solved by using fuzzy logic theorem [8]. Fuzzy logic theory is used to estimate the system's dynamics. To estimate the system dynamics, performance-based fuzzy switching feedback linearization controller is designed. This methodology is based on estimated nonlinear dynamic parameters by Mamdani fuzzy inference system. Pure feedback linearization controller and proposed methodology have difficulty in tune the controller's coefficient. It is possible to solve this problem by combining proposed methodology and gradient descent optimization (GDO). This method is based on resolve the switching feedback linearization controller $(\varphi)$. Lyapunov stability is proved in fuzzy feedback linearization controller based on switching function [15-16].

Most important challenges to control nonlinear system are stability and robustness. Feedback linearization controller is one of nonlinear controller; this controller has good XYZ position and orientation (POSE) in certain system. To eliminate this challenge artificial intelligence (AI) based on fuzzy inference system is used; this method can estimate the uncertainty. To proof stability based on LYAPUNOV formulation switching methodology is applied to AI based computed torque controller. This method is guarantee stability and limitation robustness. To reduce the dependence on controller's coefficient (e.g. sliding surface) PID baseline method is used and applied to AI based switching computed torque methodology.

This paper is organized as follows: In section 2, main subject of modeling robot manipulator formulation, forward kinematics, feedback linearization method, switching stable methodology, baseline methodology and fuzzy logic method are presented. Detail of proposed methodology is presented in section 3 . In section 4 , the simulation result is presented and finally in section 5, the conclusion is presented.

\section{THEORY}

\section{A. Dynamic Formulation of PUMA robot Arm}

Dynamic modeling of robot manipulators is used to describe the behavior of robot manipulator such as linear or nonlinear dynamic behavior, design of model based controller such as pure sliding mode controller which design this controller is based on nonlinear dynamic equations, and for simulation. The dynamic modeling describes the relationship between joint motion, velocity, and accelerations to force/torque or current/voltage and also it can be used to describe the particular dynamic effects (e.g., inertia, coriolios, centrifugal, and the other parameters) to behavior of system[1]. The Unimation PUMA 560 serially links robot manipulator was used as a basis, because this robot manipulator is widely used in industry and academic. It has a nonlinear and uncertain dynamic parameters serial link 6 degrees of freedom (DOF) robot manipulator [17-21].

The equation of an $n-D O F$ robot manipulator governed by the following equation $[1,4,22-24]$ :

$$
M(q) \ddot{q}+N(q, \dot{q})=\tau
$$


Where $\tau$ is actuation torque, $\mathrm{M}(\mathrm{q})$ is a symmetric and positive define inertia matrix, $N(q, \dot{q})$ is the vector of nonlinearity term. This robot manipulator dynamic equation can also be written in a following form [25-31]:

$$
\tau=M(q) \ddot{q}+B(q)[\dot{q} \dot{q}]+C(q)[\dot{q}]^{2}+G(q)
$$

Where $\mathrm{B}(\mathrm{q})$ is the matrix of coriolios torques, $\mathrm{C}(\mathrm{q})$ is the matrix of centrifugal torques, and $\mathrm{G}(\mathrm{q})$ is the vector of gravity force. The dynamic terms in equation (2) are only manipulator position. This is a decoupled system with simple second order linear differential dynamics. In other words, the component $\ddot{q}$ influences, with a double integrator relationship, only the joint variable $q_{i}$, independently of the motion of the other joints. Therefore, the angular acceleration is found as to be [3, 31-50]:

$$
\ddot{q}=M^{-1}(q) \cdot\{\tau-N(q, \dot{q})\}
$$

This technique is very attractive from a control point of view.

\section{B. Forward Kinematics of PUMA robot}

Calculate the relationship between rigid bodies and end-effector without any forces is called Robot manipulator Kinematics. Study of this part is pivotal to calculate accurate dynamic part, to design with an acceptable performance controller, and in real situations and practical applications. As expected the study of manipulator kinematics is divided into two main parts: forward and inverse kinematics. Forward kinematics has been used to find the position and orientation of task (end-effector) frame when angles and/or displacement of joints are known. Inverse kinematics has been used to find possible joints variable (displacements and angles) when all position and orientation of end-effector be active [1].

The main target in forward kinematics is calculating the following function:

$$
\boldsymbol{\Psi}(\boldsymbol{X}, \boldsymbol{q})=\mathbf{0}
$$

Where $\Psi(.) \in R^{n}$ is a nonlinear vector function, $X=\left[X_{1}, X_{2}, \ldots \ldots, X_{l}\right]^{T}$ is the vector of task space variables which generally endeffector has six task space variables, three position and three orientation, $q=$ $\left[q_{1}, q_{2}, \ldots, q_{n}\right]^{T}$ is a vector of angles or displacement, and finally $n$ is the number of actuated joints. The Denavit-Hartenberg (D-H) convention is a method of drawing robot manipulators free body diagrams. DenvitHartenberg (D-H) convention study is necessary to calculate forward kinematics in serial robot manipulator. The first step to calculate the serial link robot manipulator forward kinematics is link description; the second step is finding the $\mathrm{D}-\mathrm{H}$ convention after the frame attachment and finally finds the forward kinematics. Forward kinematics is a $4 \times 4$ matrix which $3 \times 3$ of them shows the rotation matrix, $3 \times 1$ of them is shown the position vector and last four cells are scaling factor[1, 6]. Singularity is a location in the robot manipulator's workspace which the robot manipulator loses one or more degrees of freedom in Cartesian space. Singularities are one of the most important challenges in inverse kinematics which Cheng et al., have proposed a method to solve this problem [13]. A systematic Forward Kinematics of robot manipulator solution is the main target of this part. The first step to compute Forward Kinematics (F.K) of robot manipulator is finding the standard D-H parameters. The following steps show the systematic derivation of the standard D-H parameters.

1. Locate the robot arm

2. Label joints

3. Determine joint rotation or translation $(\theta$ or $d)$

4. Setup base coordinate frames.

5. Setup joints coordinate frames.

6. Determine $\alpha_{i}$, that $\alpha_{i}$, link twist, is the angle between $Z_{i}$ and $Z_{i+1}$ about an $X_{i}$.

7. Determine $d_{i}$ and $a_{i}$, that $a_{i}$, link length, is the distance between $Z_{i}$ and $Z_{i+1}$ along $X_{i}$. $d_{i}$, offset, is the distance between $X_{i-1}$ and $X_{i}$ along $Z_{i}$ axis.

8. Fill up the D-H parameters table.

The second step to compute Forward kinematics for robot manipulator is finding the rotation matrix $\left(R_{n}^{0}\right)$. The rotation matrix from $\left\{F_{i}\right\}$ to $\left\{F_{i-1}\right\}$ is given by the following equation;

$$
R_{i}^{i-1}=U_{i\left(\theta_{i}\right)} V_{i\left(\alpha_{i}\right)}
$$

Where $U_{i\left(\theta_{i}\right)}$ is given by the following equation [1];

$$
U_{i\left(\theta_{i}\right)}=\left[\begin{array}{ccc}
\cos \left(\theta_{i}\right) & -\sin \left(\theta_{i}\right) & 0 \\
\sin \left(\theta_{i}\right) & \cos \left(\theta_{i}\right) & 0 \\
0 & 0 & 1
\end{array}\right]
$$

and $V_{i\left(\alpha_{i}\right)}$ is given by the following equation [1];

$$
V_{i\left(\theta_{i}\right)}=\left[\begin{array}{ccc}
1 & 0 & 0 \\
0 & \cos \left(\alpha_{i}\right) & -\sin \left(\alpha_{i}\right) \\
0 & \sin \left(\alpha_{i}\right) & \cos \left(\alpha_{i}\right)
\end{array}\right]
$$

So $\left(R_{n}^{0}\right)$ is given by [1]

$$
R_{n}^{0}=\left(U_{1} V_{1}\right)\left(U_{2} V_{2}\right) \ldots \ldots\left(U_{n} V_{n}\right)
$$

The third step to compute the forward kinematics for robot manipulator is finding the displacement vector $d_{n}^{0}$, that it can be calculated by the following equation [1]

$$
\begin{aligned}
& \boldsymbol{d}_{n}^{\mathbf{0}} \\
& =\left(U_{1} S_{1}\right)+\left(U_{1} V_{1}\right)\left(U_{2} S_{2}\right)+\cdots \\
& +\left(U_{1} V_{1}\right)\left(U_{2} V_{2}\right) \ldots\left(U_{n-1} V_{n-1}\right)\left(U_{n} S_{n}\right)
\end{aligned}
$$

The forth step to compute the forward kinematics for robot manipulator is calculate the transformation ${ }_{n}^{0} T$ by the following formulation [1]

$$
{ }_{n}^{0} T={ }_{1}^{0} T \cdot{ }_{2}^{1} T \cdot{ }_{3}^{2} T \ldots \ldots .{ }_{n}^{n-1} T=\left[\begin{array}{cc}
R_{n}^{0} & d_{n}^{0} \\
0 & 1
\end{array}\right]
$$




\section{Feedback linearization Control}

Feedback linearization controller (FLC) is a powerful nonlinear method, which it is widely used in control of robot manipulator. It is based on feedback linearization and computes the required results using the nonlinear feedback control law. This controller works very well when all dynamic and physical parameters are known. In practice, most of physical systems parameters are unknown or time variant, therefore, CTC must to mixed to the other methodology to compensate dynamic equation of robot manipulator. VIVAS and MOSQUERA have proposed a feedback linearization controller for tracking response in uncertain environment. They compared this method and predictive methodology, however both controllers have been used in feedback linearization, but predictive strategy gives better result as a performance in above research. If an alternative linear state-space equation in the form $\dot{x}=A x+B U$ can be defined as

$$
\dot{x}=\left[\begin{array}{ll}
\mathbf{0} & I \\
\mathbf{0} & \mathbf{0}
\end{array}\right] x+\left[\begin{array}{l}
\mathbf{0} \\
I
\end{array}\right] U
$$

With $\boldsymbol{U}=\boldsymbol{B}(\boldsymbol{q})[\dot{\boldsymbol{q}} \dot{\boldsymbol{q}}]+\boldsymbol{C}(\boldsymbol{q})[\dot{\boldsymbol{q}}]^{2}+\boldsymbol{G}(\boldsymbol{q})$ and this is known as the Brunousky canonical form. By equation (11) and (12) the Brunousky canonical form can be written in terms of the state $\boldsymbol{x}=\left[\boldsymbol{e}^{T} \dot{\boldsymbol{e}}^{T}\right]^{T}$ as [1]:

$$
\frac{d}{d t}\left[\begin{array}{c}
e \\
\dot{e}
\end{array}\right]=\left[\begin{array}{ll}
0 & I \\
0 & 0
\end{array}\right] \cdot\left[\begin{array}{l}
e \\
\dot{e}
\end{array}\right]+\left[\begin{array}{l}
0 \\
I
\end{array}\right] U
$$

This is a nonlinear feedback control law that guarantees tracking of robot manipulator trajectory. Selecting proportional-plus-derivative (PD) feedback for $\mathrm{U}(\mathrm{t})$ results in the PD-FELC ;

$$
\begin{aligned}
& \tau=M(q)\left(\ddot{q}_{d}+K_{v} \dot{e}+K_{p} e\right)+ \\
& N(q, \dot{q})
\end{aligned}
$$

According to the linear system theory, convergence of the tracking error to zero is guaranteed. Where $\boldsymbol{K}_{\boldsymbol{p}}$ and $\boldsymbol{K}_{\boldsymbol{v}}$ are the controller gains.

\section{Switching Stable Methodology}

The main goal to design this methodology is train to the desired state; $\boldsymbol{x}_{\boldsymbol{d}}=\left[\boldsymbol{x}_{d}, \dot{\boldsymbol{x}}_{d}, \ddot{\boldsymbol{x}}_{\boldsymbol{d}}, \ldots, \boldsymbol{x}_{\boldsymbol{d}}{ }^{(\boldsymbol{n}-1)}\right]^{T}$, and trucking error vector is defined by [6]:

$$
\widetilde{x}=x-x_{d}=\left[\widetilde{x}, \ldots, \widetilde{x}^{(n-1)}\right]^{T}
$$

A time-varying variable structure (VS) surface $\boldsymbol{s}(\boldsymbol{x}, \boldsymbol{t})$ in the state space $\boldsymbol{R}^{\boldsymbol{n}}$ is given by [6]:

$$
s(x, t)=\left(\frac{d}{d t}+\lambda\right)^{n-1} \widetilde{x}=0
$$

Where $\lambda$ is the positive constant and calculate it is play important role to have the best performance. The main target in this methodology is kept the VS surface slope $\boldsymbol{s}(\boldsymbol{x}, \boldsymbol{t})$ near to the zero. Therefore, one of the common strategies is to find input $\boldsymbol{U}$ outside of $\boldsymbol{s}(\boldsymbol{x}, \boldsymbol{t})$ [6].

$$
\frac{1}{2} \frac{d}{d t} s^{2}(x, t) \leq-\zeta|s(x, t)|
$$

where $\zeta$ is positive constant.

$$
\text { If } \mathbf{S}(\mathbf{0})>\mathbf{0} \rightarrow \frac{\mathrm{d}}{\mathrm{dt}} \mathbf{S}(\mathrm{t}) \leq-\zeta
$$

To eliminate the derivative term, it is used an integral term from $\mathrm{t}=0$ to $\mathrm{t}=\boldsymbol{t}_{\text {reach }}$

$$
\begin{array}{r}
\int_{t=0}^{t=t_{\text {reach }}} \frac{d}{d t} S(t) \leq-\int_{t=0}^{t=t_{\text {reach }}} \eta \rightarrow S\left(t_{\text {reach }}\right) \\
-S(0) \leq-\zeta\left(t_{\text {reach }}-0\right)
\end{array}
$$

Where $t_{\text {reach }}$ is the time that trajectories reach to the VS surface so, suppose $\mathrm{S}\left(t_{\text {reach }}=0\right)$ defined as;

$$
0-S(0) \leq-\eta\left(t_{\text {reach }}\right) \rightarrow t_{\text {reach }} \leq \frac{S(0)}{\zeta}
$$

And

$$
\text { if } \begin{aligned}
\boldsymbol{S}(\mathbf{0})<0 \rightarrow 0- & S(0) \leq-\eta\left(\boldsymbol{t}_{\text {reach }}\right) \\
& \rightarrow \boldsymbol{S}(\mathbf{0}) \leq-\zeta\left(\boldsymbol{t}_{\text {reach }}\right) \\
& \rightarrow \boldsymbol{t}_{\text {reach }} \leq \frac{|\boldsymbol{S}(\mathbf{0})|}{\boldsymbol{\eta}}
\end{aligned}
$$

Equation (11) guarantees time to reach the VS surface is smaller than $\frac{|\boldsymbol{S}(\mathbf{0})|}{\zeta}$ since the trajectories are outside of $S(t)$.

$$
\text { if } S_{t_{\text {reach }}}=S(0) \rightarrow \operatorname{error}\left(x-x_{d}\right)=0
$$

suppose $\mathrm{S}$ is defined as [7-19]

$$
\begin{aligned}
s(x, t)=\left(\frac{d}{d t}+\lambda\right) & \tilde{x} \\
& =\left(\dot{\mathbf{x}}-\dot{\mathbf{x}}_{\mathbf{d}}\right)+\lambda\left(\mathbf{x}-\mathbf{x}_{\mathrm{d}}\right)
\end{aligned}
$$

The derivation of $\mathrm{S}$, namely, $\dot{S}$ can be calculated as the following [20-50];

$$
\dot{S}=\left(\ddot{\mathbf{x}}-\ddot{\mathbf{x}}_{\mathbf{d}}\right)+\lambda\left(\dot{\mathbf{x}}-\dot{\mathbf{x}}_{\mathbf{d}}\right)
$$

\section{E. Based Line Methodology}

The design of a baseline methodology to control the position and orientation of robot manipulator was very straight forward. Since there was an output from the torque, this means that there would be three inputs into the baseline controller. In a typical PID method, the controller corrects the sliding surface between the desired input value and the measured value.

$$
s(x, t)=\left(\frac{d}{d t}+\lambda+\frac{1}{S}\right) \quad \tilde{x}
$$




$$
\tau_{\alpha}=K_{p_{a}} S_{1}+K_{V_{a}} \dot{S_{1}}+K_{I_{a}} \sum S_{1}
$$

\section{F. Fuzzy Logic Methodology}

Based on foundation of fuzzy logic methodology; fuzzy logic controller has played important rule to design nonlinear controller for nonlinear and uncertain systems [21-33]. However the application area for fuzzy control is really wide, the basic form for all command types of controllers consists of; Input fuzzification (binary-tofuzzy $[\mathrm{B} / \mathrm{F}]$ conversion)

Fuzzy rule base (knowledge base), Inference engine and Output defuzzification (fuzzy-to-binary [F/B] conversion). Figure 1 is shown a fuzzy controller part.

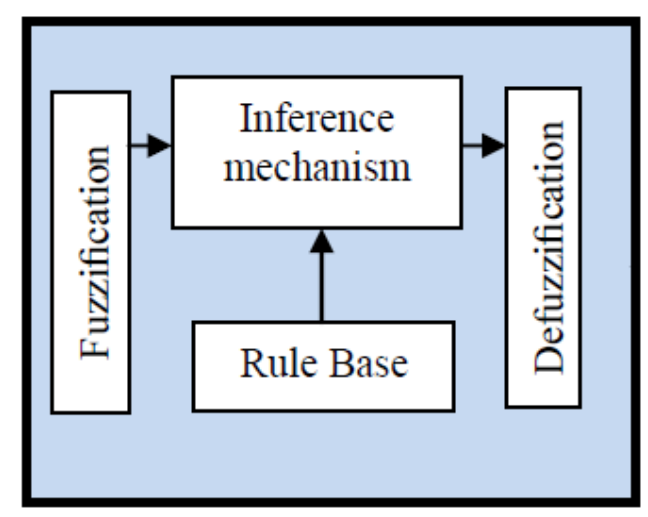

Fig 1: Fuzzy Controller Part

The fuzzy inference engine offers a mechanism for transferring the rule base in fuzzy set which it is divided into two most important methods, namely, Mamdani method and Sugeno method. Mamdani method is one of the common fuzzy inference systems and he designed one of the first fuzzy controllers to control of system engine. Mamdani's fuzzy inference system is divided into four major steps: fuzzification, rule evaluation, aggregation of the rule outputs and defuzzification. Michio Sugeno use a singleton as a membership function of the rule consequent part. The following definition shows the Mamdani and Sugeno fuzzy rule base

\section{if $x$ is $A$ and $y$ is $B$ then $z$ is $C$ 'mamdani' \\ if $x$ is $A$ and $y$ is $B$ then $z$ is $f(x, y)$ 'sugeno'}

When $x$ and $y$ have crisp values fuzzification calculates the membership degrees for antecedent part. Rule evaluation focuses on fuzzy operation $(A N D / O R)$ in the antecedent of the fuzzy rules. The aggregation is used to calculate the output fuzzy set and several methodologies can be used in fuzzy logic controller aggregation, namely, Max-Min aggregation, Sum-Min aggregation, Max-bounded product, Max-drastic product, Max-bounded sum, Max-algebraic sum and Min-max. Two most common methods that used in fuzzy logic controllers are Max-min aggregation and Sum-min aggregation. Max-min aggregation defined as below;

$$
\begin{aligned}
& \mu_{U}\left(x_{k}, y_{k}, U\right)=\mu_{\cup i=1}^{r} F R^{i}\left(x_{k}, y_{k}, U\right) \\
& =\max \left\{\min _{i=1}^{r}\left[\mu_{R}\left(x_{k}, y_{k}\right), \mu_{p_{m}}(U)\right]\right\}
\end{aligned}
$$

The Sum-min aggregation defined as below

$$
\begin{aligned}
& \mu_{U}\left(x_{k}, y_{k}, U\right)=\mu_{\cup i=1}^{r} F R^{i}\left(x_{k}, y_{k}, U\right) \\
& =\sum \min _{i=1}^{r}\left[\mu_{R p q}\left(x_{k}, y_{k}\right), \mu_{p_{m}}(U)\right]
\end{aligned}
$$

where $r$ is the number of fuzzy rules activated by $x_{k}$ and $y_{k}$ and also $\mu_{\cup_{i=1}^{r} F R^{i}}\left(x_{k}, y_{k}, U\right)$ is a fuzzy interpretation of $i-t h$ rule. Defuzzification is the last step in the fuzzy inference system which it is used to transform fuzzy set to crisp set. Consequently defuzzification's input is the aggregate output and the defuzzification's output is a crisp number. Centre of gravity method (COG) and Centre of area method (COA) are two most common defuzzification methods, which $C O G$ method used the following equation to calculate the defuzzification

$$
\operatorname{COG}\left(x_{k}, y_{k}\right)=\frac{\sum_{i} U_{i} \sum_{j=1}^{r} \cdot \mu_{u}\left(x_{k}, y_{k}, U_{i}\right)}{\sum_{i} \sum_{j=1}^{r} \cdot \mu_{u}\left(x_{k}, y_{k}, U_{i}\right)}
$$

and $C O A$ method used the following equation to calculate the defuzzification

$$
\operatorname{COA}\left(x_{k}, y_{k}\right)=\frac{\sum_{i} U_{i} \cdot \mu_{u}\left(x_{k}, y_{k}, U_{i}\right)}{\sum_{i} \mu_{U} \cdot\left(x_{k}, y_{k}, U_{i}\right)}
$$

Where $\operatorname{COG}\left(x_{k}, y_{k}\right)$ and $\operatorname{COA}\left(x_{k}, y_{k}\right)$ illustrates the crisp value of defuzzification output, $U_{i} \in U$ is discrete element of an output of the fuzzy set, $\mu_{U} \cdot\left(x_{k}, y_{k}, U_{i}\right)$ is the fuzzy set membership function, and $r$ is the number of fuzzy rules.

\section{METHODOLOGY}

\section{Design switching feedback linearization controller}

Proposed methodology is focused on applied switching method in feedback linearization controller to increased stability of the main controller. Switching methodology is a nonlinear robust and stable method and feedback linearization controller is a nonlinear controller but it has a challenge in stability and robustness especially in presence of uncertainty and disturbance. Based on (13) to improve stability switching formulation is applied to CTC;

$$
\begin{aligned}
\tau=M(q) \times s \boldsymbol{g} & \left(\ddot{\boldsymbol{q}}_{d}+K_{v}\left(\left(\ddot{\mathbf{x}}-\ddot{\mathbf{x}}_{\mathrm{d}}\right)\right.\right. \\
& \left.+\lambda\left(\dot{\mathbf{x}}-\dot{\mathbf{x}}_{\mathrm{d}}\right)\right) \\
& +\boldsymbol{K}_{\boldsymbol{p}}\left(\left(\dot{\mathbf{x}}-\dot{\mathbf{x}}_{\mathrm{d}}\right)\right. \\
& \left.\left.+\lambda\left(\mathbf{x}-\mathbf{x}_{\mathrm{d}}\right)\right)\right) \\
& +\boldsymbol{N}(\boldsymbol{q}, \dot{\boldsymbol{q}})
\end{aligned}
$$


Based on (25) to reduce the dependence of controller to coefficients controller such as $K_{p}, K_{v}, \lambda$ baseline methodology is used. Therefore based on (31) and (25);

$$
\begin{aligned}
\tau=M(q) \times s g n & \ddot{q}_{d}+K_{v}\left(\left(\ddot{\mathbf{x}}-\ddot{\mathbf{x}}_{\mathrm{d}}\right)\right. \\
& \left.+\lambda\left(\dot{\mathbf{x}}-\dot{\mathbf{x}}_{\mathrm{d}}\right)\right) \\
& +K_{p}\left(\left(\dot{\mathbf{x}}-\dot{\mathbf{x}}_{\mathrm{d}}\right)\right. \\
& \left.\left.+\lambda\left(\mathbf{x}-\mathbf{x}_{\mathrm{d}}\right)\right)\right) \\
& \times\left(K_{p_{a}} S_{1}+K_{V_{a}}{\dot{S_{1}}}\right. \\
& \left.+K_{I_{a}} \sum S_{1}\right)+N(q, \dot{q})
\end{aligned}
$$

To resolve uncertain problem this research is focused on to design SISO sliding mode switching computed torque like methodology. The firs type of fuzzy systems is given by

$$
f(x)=U_{f u z z y}=\sum_{l=1}^{M} \theta^{T} \zeta(x)
$$

where $\boldsymbol{\theta}^{\boldsymbol{T}}$ is adjustable parameter (gain updating factor) and $\boldsymbol{\zeta}(\boldsymbol{x})$ is defined by

$$
\zeta(x)=\frac{\sum_{i} \mu\left(x_{i}\right) x_{i}}{\sum_{i} \mu\left(x_{i}\right)}
$$

Where $\boldsymbol{\mu}\left(\boldsymbol{x}_{\boldsymbol{i}}\right)$ is membership function.

The second type of fuzzy systems is given by

$$
=\frac{\sum_{l=1}^{M} \theta^{l}\left[\prod_{i=1}^{n} \exp \left(-\left(\frac{x_{i}-\alpha_{i}^{l}}{\delta_{i}^{l}}\right)^{2}\right)\right]}{\sum_{l=1}^{M}\left[\prod_{i=1}^{n} \exp \left(-\left(\frac{x_{i}-\alpha_{i}^{l}}{\delta_{i}^{l}}\right)^{2}\right)\right]}
$$

Where $\theta^{l}, \alpha_{i}^{l}$ and $\delta_{i}^{l}$ are all adjustable parameters. $\boldsymbol{\tau}_{\text {fuzzy }}$ is defined as follows;

$$
\tau_{f u z z y}=\sum_{l=1}^{M} \theta^{T} \zeta(x)=N(q, \dot{q})
$$

Where;

$$
\begin{aligned}
& \ominus^{T}=\left(\theta_{1}, \ldots, \theta_{m}\right)^{T}= \\
& {\left[\begin{array}{c}
\theta_{1}^{1}, \theta_{1}^{2}, \ldots, \theta_{1}^{M} \\
\theta_{2}^{1}, \theta_{2}^{2}, \ldots, \theta_{2}^{M} \\
\vdots \\
\theta_{m}^{1}, \theta_{m}^{2}, \ldots, \theta_{m}^{M}
\end{array}\right]}
\end{aligned}
$$

Based on LYAPUNOV formulation to proof the stability, researcher must to calculate the $V$ and $\dot{V}$. Based on this formulation this system is stable if $\dot{V}<0, S \neq 0$.

\section{RESULTS AND DISCUSSION}

In this research, proposed controller is used to test the output position and orientation. To test the validity this method is compared with computed torque methodology in certain and uncertain environment.

Optimization the proposed method: in proposed methodology; controller's performance are depending on the PID coefficient $K_{p}, K_{v}, K_{i}$ and variable structure slope coefficient $(\lambda)$. These four coefficients are computed by Gradient Descent Algorithm optimization; Figure 2 and Figure 3.

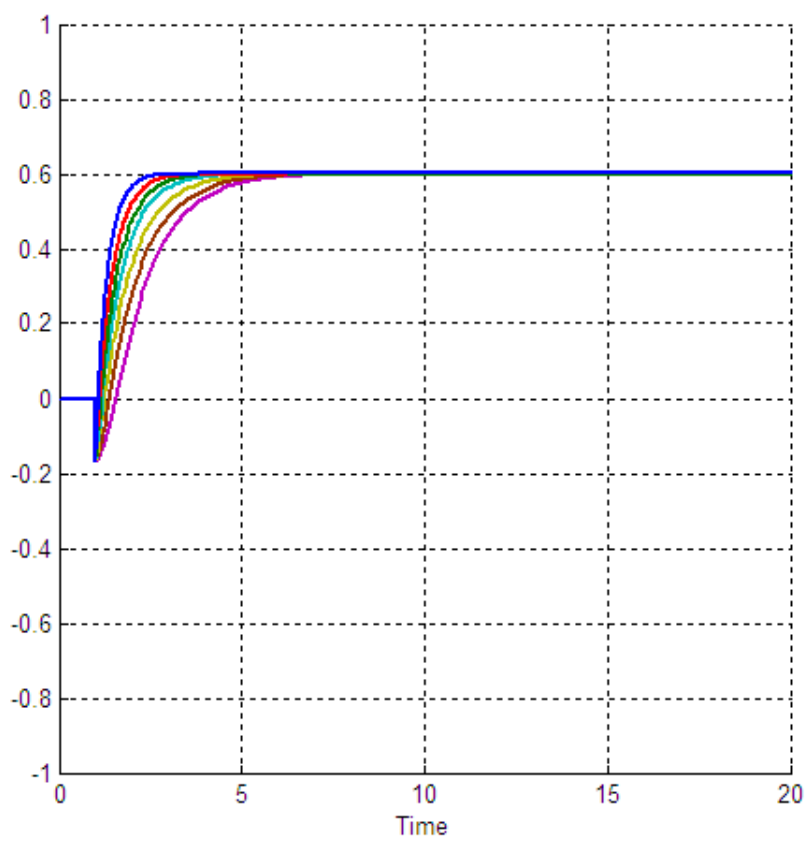

Fig 2: Trajectory following Gradient descent optimization

Position and Orientation Test: Figures 4 and 5 are shown the XYZ trajectory following in pure feedback linearization controller and proposed controller. Based on these two figures, proposed methodology has better performance to better enforcement of the order. 


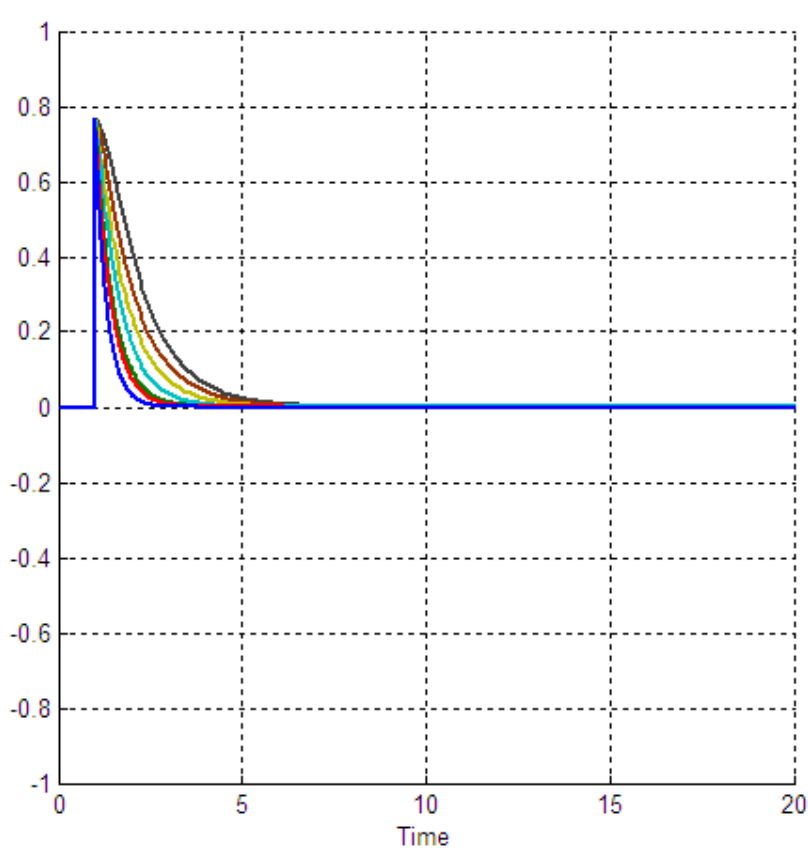

Fig 3: Error's Gradient descent optimization

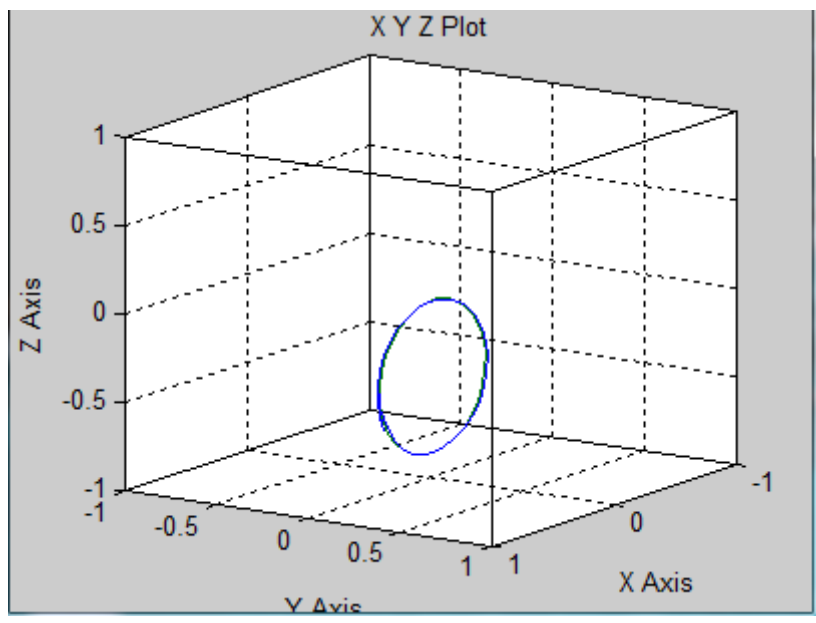

Fig 4: Proposed position and orientation in 3D dimensions

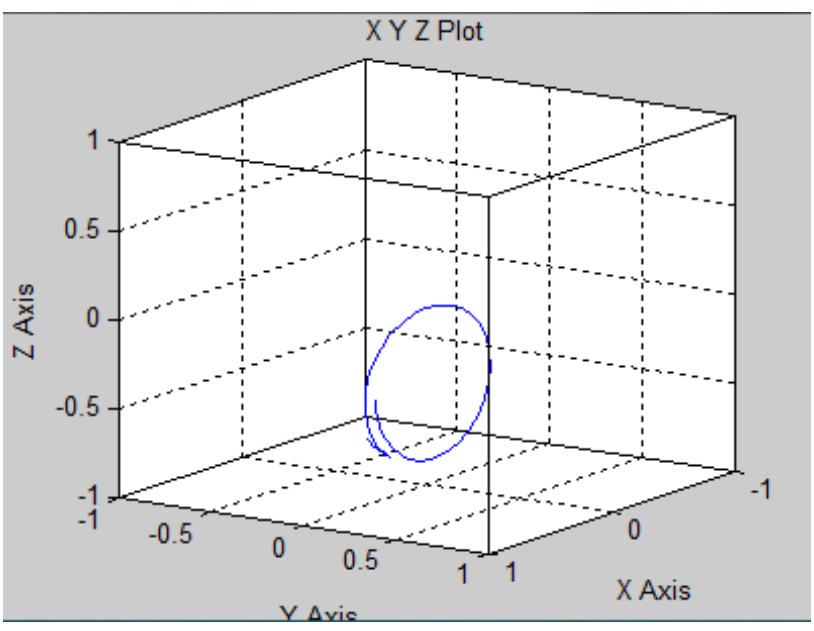

Fig 5: CTC position and orientation in 3D dimensions
It may be claimed that however computed torque method is used in many research and industry but proposed method has a better XYZ position and orientation (POSE). The data indicates that proposed method can guarantee the stability and minimal error.

Disturbance Rejection: Figures 6 and 7 are shown the power disturbance and external noise elimination in proposed method and CTC. As a matter of fact the disturbance rejection is used to test the robustness of these two methods. Surely after applied different external noise in these two methods it found fairly fluctuations in POSE responses. Actually one of the main advantages of proposed methodology is stability in presence of external disturbance. A further advantage of proposed method is increase the robustness compared to CTC.

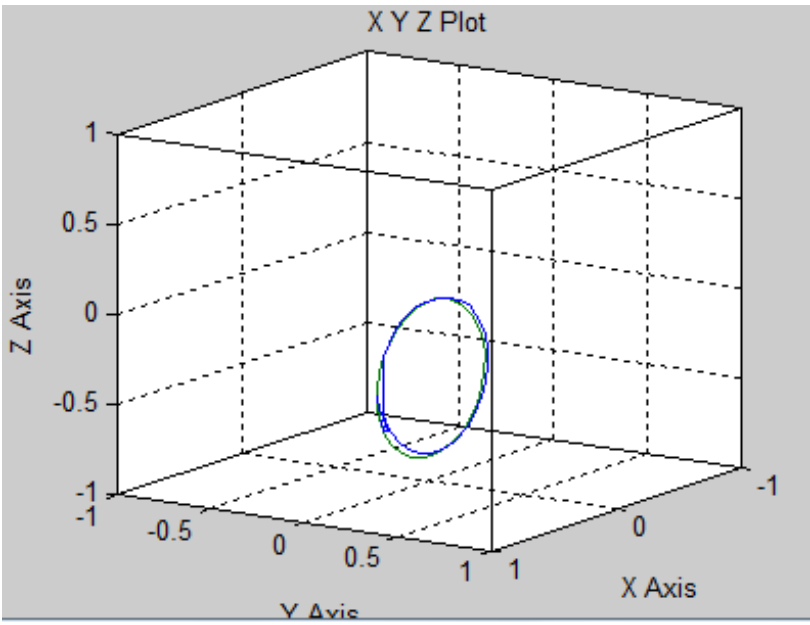

Fig 6: Disturbance rejection in proposed position and orientation in $3 \mathrm{D}$ dimensions

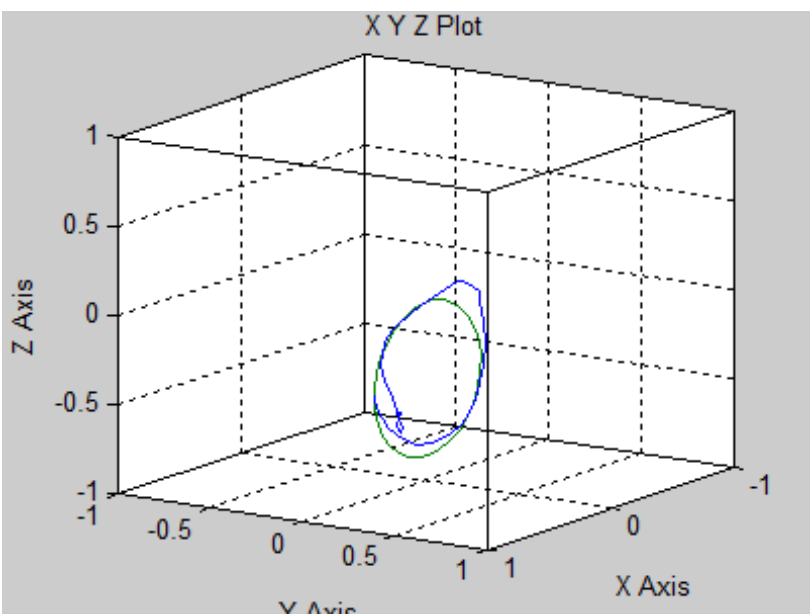

Fig 7: Disturbance rejection in CTC position and orientation in $3 \mathrm{D}$ dimensions

Based on Figure 6, baseline and switching methodology caused to increase the stability and robustness and it can eliminate the limited external disturbance. 


\section{CONCLUSION}

Refer to this research, design a baseline artificial intelligence based switching computed torque methodology is proposed to tune the POSE in PUMA robot manipulator. At first pure feedback linearization controller is design for POSE tune in PUMA robot. This method has two important challenge; stability and robustness because this method is work based on nonlinear dynamic formulation. Fuzzy inference engine is used to resolve uncertainty problem. This methodology is based on applied fuzzy logic in equivalent nonlinear dynamic part to estimate unknown parameters. To solve stability challenge in above method switching methodology is used base on LYAPUNOV formulation. However this method is very good but it is depending on variable structure slope, to solve this challenge baseline methodology is applied to AI based switching computed torque methodology. Eventually gradient descent optimization is applied to proposed methodology to tune all four parameters. The POSE results demonstrate that the gradient descent proposed method is a partly model base method which works well in certain and partly uncertain system.

\section{ACKNOWLEDGMENT}

The authors would like to thank the anonymous reviewers for their careful reading of this paper and for their helpful comments. This work was supported by the SSP Research and Development Corporation Program of Iran under grant no. 2012-Persian Gulf-3C.

\section{REFERENCES}

[1] T. R. Kurfess, Robotics and automation handbook: CRC, 2005.

[2] J. J. E. Slotine and W. Li, Applied nonlinear control vol. 461: Prentice hall Englewood Cliffs, NJ, 1991.

[3] B. Siciliano and O. Khatib, Springer handbook of robotics: Springer-Verlag New York Inc, 2008.

[4] F. T. Cheng, T. L. Hour, Y. Y. Sun and T. H. Chen, "Study and resolution of singularities for a 6-DOF PUMA manipulator," Systems, Man, and Cybernetics, Part B: Cybernetics, IEEE Transactions on, No. 2, vol. 27, pp. 332-343, 2002.

[5] M. W. Spong and M. Vidyasagar, Robot dynamics and control: Wiley-India, 2009.

[6] A. Vivas and V. Mosquera, "Predictive functional control of a PUMA robot," Conference Proceedings, 2005.

[7] D. Nguyen-Tuong, M. Seeger and J. Peters, "Computed torque control with nonparametric regression models," IEEE conference proceeding, 2008, pp. 212-217.

[8] Farzin Piltan , N. Sulaiman, Zahra Tajpaykar, Payman Ferdosali, Mehdi Rashidi, "Design Artificial Nonlinear Robust Controller Based on CTLC and FSMC with Tunable Gain," International
Journal of Robotic and Automation, 2 (3): 205-220, 2011.

[9] Farzin Piltan, A. R. Salehi and Nasri B Sulaiman.," Design artificial robust control of second order system based on adaptive fuzzy gain scheduling," world applied science journal (WASJ), 13 (5): 1085-1092, 2011.

[10] Farzin Piltan, N. Sulaiman, Atefeh Gavahian, Samira Soltani, Samaneh Roosta, "Design Mathematical Tunable Gain PID-Like Sliding Mode Fuzzy Controller with Minimum Rule Base," International Journal of Robotic and Automation, 2 (3): 146-156, 2011.

[11] Farzin Piltan , A. Zare, Nasri B. Sulaiman, M. H. Marhaban and R. Ramli, , "A Model Free Robust Sliding Surface Slope Adjustment in Sliding Mode Control for Robot Manipulator," World Applied Science Journal, 12 (12): 2330-2336, 2011.

[12] Farzin Piltan , A. H. Aryanfar, Nasri B. Sulaiman, M. H. Marhaban and R. Ramli "Design Adaptive Fuzzy Robust Controllers for Robot Manipulator," World Applied Science Journal, 12 (12): 23172329, 2011.

[13] Farzin Piltan, N. Sulaiman , Arash Zargari, Mohammad Keshavarz, Ali Badri , "Design PIDLike Fuzzy Controller With Minimum Rule Base and Mathematical Proposed On-line Tunable Gain: Applied to Robot Manipulator,' International Journal of Artificial intelligence and expert system, 2 (4):184-195, 2011.

[14] Farzin Piltan, Nasri Sulaiman, M. H. Marhaban and R. Ramli, "Design On-Line Tunable Gain Artificial Nonlinear Controller," Journal of Advances In Computer Research, 2 (4): 75-83, 2011.

[15] Farzin Piltan, N. Sulaiman, Payman Ferdosali, Iraj Assadi Talooki, “ Design Model Free Fuzzy Sliding Mode Control: Applied to Internal Combustion Engine," International Journal of Engineering, 5 (4):302-312, 2011.

[16] Farzin Piltan, N. Sulaiman, Samaneh Roosta, M.H. Marhaban, R. Ramli, "Design a New Sliding Mode Adaptive Hybrid Fuzzy Controller," Journal of Advanced Science \& Engineering Research , 1 (1): 115-123, 2011.

[17] Farzin Piltan, Atefe Gavahian, N. Sulaiman, M.H. Marhaban, R. Ramli, "Novel Sliding Mode Controller for robot manipulator using FPGA," Journal of Advanced Science \& Engineering Research, 1 (1): 1-22, 2011.

[18] Farzin Piltan, N. Sulaiman, A. Jalali \& F. Danesh Narouei, "Design of Model Free Adaptive Fuzzy Computed Torque Controller: Applied to Nonlinear Second Order System," International Journal of Robotics and Automation, 2 (4):232-244, 2011.

[19] Farzin Piltan, N. Sulaiman, Iraj Asadi Talooki, Payman Ferdosali, "Control of IC Engine: Design a Novel MIMO Fuzzy Backstepping Adaptive Based Fuzzy Estimator Variable Structure Control ," International Journal of Robotics and Automation, 2 (5):360-380, 2011. 
[20] Farzin Piltan, N. Sulaiman, Payman Ferdosali, Mehdi Rashidi, Zahra Tajpeikar, "Adaptive MIMO Fuzzy Compensate Fuzzy Sliding Mode Algorithm: Applied to Second Order Nonlinear System," International Journal of Engineering, 5 (5): 380-398, 2011.

[21] Farzin Piltan, N. Sulaiman, Hajar Nasiri, Sadeq Allahdadi, Mohammad A. Bairami, "Novel Robot Manipulator Adaptive Artificial Control: Design a Novel SISO Adaptive Fuzzy Sliding Algorithm Inverse Dynamic Like Method," International Journal of Engineering, 5 (5): 399-418, 2011.

[22] Farzin Piltan, N. Sulaiman, Sadeq Allahdadi, Mohammadali Dialame, Abbas Zare, "Position Control of Robot Manipulator: Design a Novel SISO Adaptive Sliding Mode Fuzzy PD Fuzzy Sliding Mode Control," International Journal of Artificial intelligence and Expert System, 2 (5):208-228, 2011. [23]Farzin Piltan, SH. Tayebi HAGHIGHI, N. Sulaiman, Iman Nazari, Sobhan Siamak, "Artificial Control of PUMA Robot Manipulator: A-Review of Fuzzy Inference Engine And Application to Classical Controller ," International Journal of Robotics and Automation, 2 (5):401-425, 2011.

[24] Farzin Piltan, N. Sulaiman, Abbas Zare, Sadeq Allahdadi, Mohammadali Dialame, "Design Adaptive Fuzzy Inference Sliding Mode Algorithm: Applied to Robot Arm," International Journal of Robotics and Automation , 2 (5): 283-297, 2011.

[25] Farzin Piltan, Amin Jalali, N. Sulaiman, Atefeh Gavahian, Sobhan Siamak, "Novel Artificial Control of Nonlinear Uncertain System: Design a Novel Modified PSO SISO Lyapunov Based Fuzzy Sliding Mode Algorithm," International Journal of Robotics and Automation, 2 (5): 298-316, 2011.

[26] Farzin Piltan, N. Sulaiman, Amin Jalali, Koorosh Aslansefat, "Evolutionary Design of Mathematical tunable FPGA Based MIMO Fuzzy Estimator Sliding Mode Based Lyapunov Algorithm: Applied to Robot Manipulator," International Journal of Robotics and Automation, 2 (5):317-343, 2011.

[27] Farzin Piltan, N. Sulaiman, Samaneh Roosta, Atefeh Gavahian, Samira Soltani, "Evolutionary Design of Backstepping Artificial Sliding Mode Based Position Algorithm: Applied to Robot Manipulator," International Journal of Engineering, 5 (5):419-434, 2011.

[28] Farzin Piltan, N. Sulaiman, S.Soltani, M. H. Marhaban \& R. Ramli, "An Adaptive sliding surface slope adjustment in PD Sliding Mode Fuzzy Control for Robot Manipulator," International Journal of Control and Automation , 4 (3): 65-76, 2011.

[29] Farzin Piltan, N. Sulaiman, Mehdi Rashidi, Zahra Tajpaikar, Payman Ferdosali, "Design and Implementation of Sliding Mode Algorithm: Applied to Robot Manipulator-A Review ," International Journal of Robotics and Automation, 2 (5):265-282, 2011.
[30] Farzin Piltan, N. Sulaiman, Amin Jalali, Sobhan Siamak, and Iman Nazari, "Control of Robot Manipulator: Design a Novel Tuning MIMO Fuzzy Backstepping Adaptive Based Fuzzy Estimator Variable Structure Control ," International Journal of Control and Automation, 4 (4):91-110, 2011.

[31] Farzin Piltan, N. Sulaiman, Atefeh Gavahian, Samaneh Roosta, Samira Soltani, "On line Tuning Premise and Consequence FIS: Design Fuzzy Adaptive Fuzzy Sliding Mode Controller Based on Lyaponuv Theory," International Journal of Robotics and Automation, 2 (5):381-400, 2011.

[32] Farzin Piltan, N. Sulaiman, Samaneh Roosta, Atefeh Gavahian, Samira Soltani, "Artificial Chattering Free on-line Fuzzy Sliding Mode Algorithm for Uncertain System: Applied in Robot Manipulator," International Journal of Engineering, 5 (5):360-379, 2011.

[33] Farzin Piltan, N. Sulaiman and I.AsadiTalooki, "Evolutionary Design on-line Sliding Fuzzy Gain Scheduling Sliding Mode Algorithm: Applied to Internal Combustion Engine," International Journal of Engineering Science and Technology, 3 (10):7301-7308, 2011.

[34] Farzin Piltan, Nasri B Sulaiman, Iraj Asadi Talooki and Payman Ferdosali.," Designing On-Line Tunable Gain Fuzzy Sliding Mode Controller Using Sliding Mode Fuzzy Algorithm: Applied to Internal Combustion Engine," world applied science journal (WASJ), 15 (3): 422-428, 2011.

[35] Farzin Piltan, N. Sulaiman, M. H. Marhaban, Adel Nowzary, Mostafa Tohidian," "Design of FPGA based sliding mode controller for robot manipulator," International Journal of Robotic and Automation, 2 (3): 183-204, 2011.

[36] Samira Soltani \& Farzin Piltan, "Design Artificial Nonlinear Controller Based on Computed Torque like Controller with Tunable Gain". World Applied Science Journal,14 (9): 1306-1312, 2011.

[37] Farzin Piltan, H. Rezaie, B. Boroomand, Arman Jahed," Design robust back stepping online tuning feedback linearization control applied to IC engine," International Journal of Advance Science and Technology, 42: 183-204, 2012.

[38] Farzin Piltan, I. Nazari, S. Siamak, P. Ferdosali ,"Methodology of FPGA-based mathematical error-based tuning sliding mode controller" International Journal of Control and Automation, 5(1): 89-110, 2012.

[39] Farzin Piltan, M. A. Dialame, A. Zare, A. Badri ,'Design Novel Lookup table changed Auto Tuning FSMC: Applied to Robot Manipulator" International Journal of Engineering, 6(1): 25-40, 2012.

[40] Farzin Piltan, B. Boroomand, A. Jahed, H. Rezaie ,"Methodology of Mathematical ErrorBased Tuning Sliding Mode Controller" International Journal of Engineering, 6(2): 96-112, 2012. 
[41] Farzin Piltan, F. Aghayari, M. R. Rashidian, M. Shamsodini, "A New Estimate Sliding Mode Fuzzy Controller for Robotic Manipulator" International Journal of Robotics and Automation, 3(1): 45-58, 2012.

[42] Farzin Piltan, M. Keshavarz, A. Badri, A. Zargari , "Design novel nonlinear controller applied to robot manipulator: design new feedback linearization fuzzy controller with minimum rule base tuning method" International Journal of Robotics and Automation, 3(1): 1-18, 2012.

[43] Piltan, F., et al. "Design sliding mode controller for robot manipulator with artificial tunable gain". Canaidian Journal of pure and applied science, 5 (2), 1573-1579, 2011.

[44] Farzin Piltan, A. Hosainpour, E. Mazlomian, M.Shamsodini, M.H Yarmahmoudi. "Online Tuning Chattering Free Sliding Mode Fuzzy Control Design: Lyapunov Approach" International Journal of Robotics and Automation, 3(3): 2012.

[45] Farzin Piltan , M.H. Yarmahmoudi, M. Shamsodini, E.Mazlomian, A.Hosainpour. " PUMA-560 Robot Manipulator Position Computed Torque Control Methods Using MATLAB/SIMULINK and Their Integration into Graduate Nonlinear Control and MATLAB Courses" International Journal of Robotics and Automation, 3(3): 2012.

[46] Farzin Piltan, R. Bayat, F. Aghayari, B. Boroomand. "Design Error-Based Linear ModelFree Evaluation Performance Computed Torque Controller" International Journal of Robotics and Automation, 3(3): 2012.

[47] Farzin Piltan, S. Emamzadeh, Z. Hivand, F. Shahriyari \& Mina Mirazaei ." PUMA-560 Robot Manipulator Position Sliding Mode Control Methods Using MATLAB/SIMULINK and Their Integration into Graduate/Undergraduate Nonlinear Control, Robotics and MATLAB Courses" International Journal of Robotics and Automation, 3(3): 2012.

[48] Farzin Piltan, J. Meigolinedjad, S. Mehrara, S. Rahmdel. "Evaluation Performance of $2^{\text {nd }}$ Order Nonlinear System: Baseline Control Tunable Gain Sliding Mode Methodology" International Journal of Robotics and Automation, 3(3): 2012.

[49] Farzin Piltan, M. Mirzaie, F. Shahriyari, Iman Nazari \& S. Emamzadeh." Design Baseline Computed Torque Controller" International Journal of Engineering, 3(3): 2012.

[50] Farzin Piltan, S. Siamak, M. A. Bairami, Iman Nazari." Gradient descent optimal chattering free sliding mode fuzzy control design: LYAPUNOV approach" International Journal of Advance Science and Technology, Vol.45: 2012.

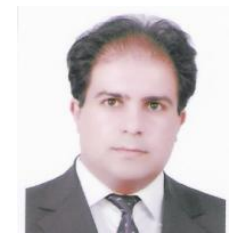

Farzin Piltan was born on 1975, Shiraz, Iran. In 2004 he is jointed the research and development company, SSP Co, Shiraz, Iran. In addition to 7 textbooks, Farzin Piltan is the main author of more than 50 scientific papers in refereed journals. He is editorial board of international journal of control and automation (IJCA), editorial board of International Journal of Intelligent System and Applications (IJISA), editorial board of IAES international journal of robotics and automation, editorial board of International Journal of Reconfigurable and Embedded Systems and reviewer of (CSC) international journal of robotics and automation. His main areas of research interests are nonlinear control, artificial control system and applied to FPGA, robotics and artificial nonlinear control and IC engine modelling and control.

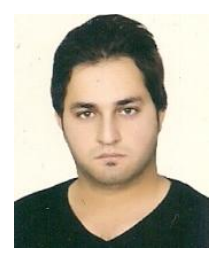

Reza Bayat is an electrical electronic researcher of research and development company SSP. Co. His main areas of research interests are nonlinear control, artificial control system and robotics.

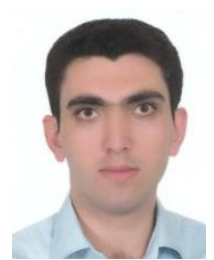

Saleh Mehara is an electrical electronic researcher of research and development company SSP. Co. His main areas of research interests are nonlinear control, artificial control system and robotics.

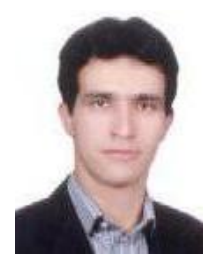

Javad Meigolinedjad is a mechanical engineer researcher of research and development company SSP. Co. He is now pursuing his Master in economic. He is an expert mechanical engineer in this company. His research activities deal with the robotics and artificial nonlinear

control. 